\title{
Ofensiva conservadora na educação superior e os desafios à formação em Serviço Social no Brasil
}

\author{
Sandra de Faria* \\ Sarah Medeiros Avelar**
}

\begin{abstract}
RESUMO: O artigo problematiza a contrarreforma da educação superior no Brasil e o seu alvo de mudança estrutural e conceitual de universidade. Objetiva contribuir com o debate crítico-analítico sobre o projeto de formação profissional propugnado nas Diretrizes Curriculares Nacionais de 1996 e a configuração do Serviço Social como área de conhecimento e avanço qualitativo inserido no contexto contraditório da Universidade. A proposta de discussão advém da hipótese de que a expansão dos cursos de Serviço Social sob a lógica privatista mercantil, com forte apelo aos valores do neoconservadorismo, é uma tendência incompatível e antípoda dos princípios, diretrizes, núcleos de fundamentação e conteúdos postulados nas Diretrizes Curriculares Nacionais de 1996.
\end{abstract}

PALAVRAS-CHAVE: Serviço Social; Educação Superior; Mercantilização; Financeirização; Conservadorismo.

\section{Conservative offensive in higher education and the challenges to training in Social Work in Brazil}

\begin{abstract}
The article discusses the counter-reform of higher education in Brazil and its target for structural and conceptual change in the university. It aims to contribute to the critical-analytical discussion on the professional training project advocated in the 1996 National Curriculum Guidelines and the configuration of Social Work as an area of knowledge and qualitative advancement inserted in the contradictory context of the University. The discussion proposal stems from the hypothesis that the expansion of Social Service courses under the mercantile privatist logic, with a strong appeal to the values of neoconservatism, is an incompatible and antipode trend of the principles, guidelines, foundations and content postulated in the Curricular Guidelines 1996 Nationals.
\end{abstract}

KEYWORDS: Social Work; Higher education; Commodification; Financialization; Conservatism.

Submetido em 24/04/2020

Aprovado em 13/05/2020

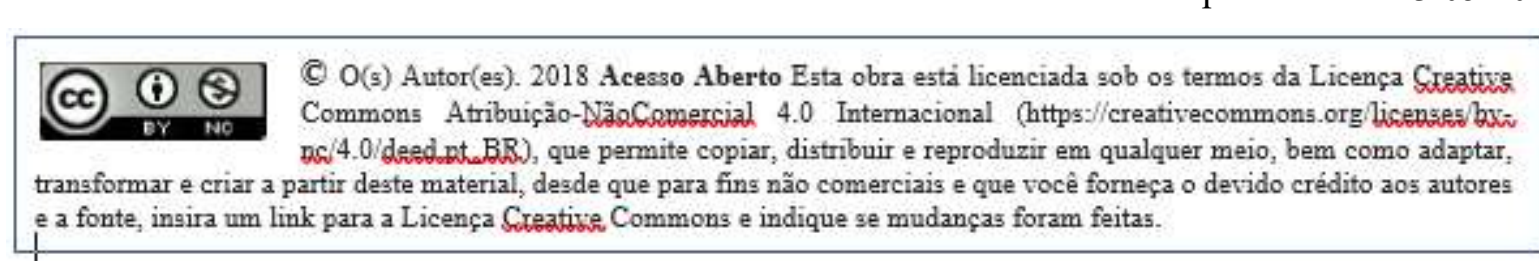

\footnotetext{
* Doutora em Serviço Social. Docente do Curso de Serviço Social e do Programa de Pós-Graduação Stricto Sensu em Serviço Social da Pontifícia Universidade Católica de Goiás. Coordenadora do Grupo de Estudos e Pesquisa em Teoria Social e Fundamentos do Serviço Social.

** Assistente Social. Graduada em Serviço Social pela Pontifícia Universidade Católica de Goiás. Mestre em Serviço Social pelo Programa de Pós-graduação Stricto Sensu em Serviço Social da Pontifícia Universidade Católica de Goiás.
} 


\section{Introdução}

É fato que, nas últimas décadas, a formação profissional em Serviço Social tem enfrentado novos desafios conjunturais, político-pedagógicos e educacionais, especialmente quanto à expansão de instituições de ensino, de cursos de graduação e de vagas, de características predominantemente de compra e venda de serviços privados, e ao significativo crescimento do ensino na modalidade à distância (EAD), primeiramente nos cursos de licenciaturas, com o objetivo de formar professores, depois, expandindo-se para outros cursos, incluindo o de Serviço Social.

A expansão dos cursos de graduação com acento na estratégia de crescimento das modalidades à distância e semipresenciais, ordenada sob a lógica da prestação de serviços e monopolizada por instituições de ensino superior privadas mercantis é uma alteração compatível com o mercado, como bem explicita Iamamoto (2015, p. 438):

Essa tendência é compatível com a premissa de que o mercado - leia-se o capital - é portador da racionalidade sociopolítica e o agente principal do bemestar da República. Ela tende a deslocar direitos sociais, entre os quais a educação superior, para o setor de prestação de serviços definido pelo mercado, segundo os critérios de produtividade, competição e eficiência, desfigurando-a e mutilando-a, ao tempo em que comprime o espaço público e amplia o espaço privado.

Em poucas partes do mundo se sobressai, nos indicadores da educação superior, como se verifica no Brasil, a realidade de uma expansão induzida pelo Estado, com amplo apoio de programas de financiamento e suporte legal às instituições de ensino superior privadas mercantis.

Essa realidade de massificação e mercantilização da educação superior pode ser verificada nos últimos censos do país. O Censo de 2018 demonstrou que 88,2\% das instituições de educação superior são privadas. São 299 IES públicas para 2.238 IES privadas. Em 2018, 3,4 milhões de alunos ingressaram em cursos de educação superior de graduação. Desse total, 83,1\% em instituições privadas (INEP, 2019). Pelo documento, observa-se ainda que o aumento no número de ingressantes em 2018 em relação a 2017 foi sustentado pelo significativo aumento nos cursos na modalidade à distância, compensando a queda registrada nos cursos presenciais. Chamam atenção os dados estatísticos de 2008 a 2018: o número de ingressos variou positivamente a 10,6\% nos cursos presenciais de graduação e triplicou $(196,6 \%)$ nos cursos à distância. E, ainda, enquanto o percentual dos ingressantes em cursos de graduação à distância em 2008 era de 19,8\%, esse percentual, em 2018, foi para quase 40\% (INEP, 2019). 
Esses são alguns dos indicadores do cenário da educação superior no Brasil e ajudam a explicar por que, nas últimas décadas, muitas IES se reestruturaram, alterando sua natureza jurídica de "sem fins lucrativos" para "com fins lucrativos", num claro movimento de aprofundamento da relação entre educação, desnacionalização e financeirização.

Trata-se de instituições de organização pulverizada e capacidade de atender a interesses corporativos e constituir oligopólios por meio de fusões e negociações de suas ações em bolsa de valores (CHAVES, 2010). São organizações e grupos amplamente favorecidos pela flexibilidade e (des)regulamentação jurídica e institucional do direito universal à educação laica e democrática, uma reivindicação histórica de movimentos em defesa da educação a ser conferida por políticas educacionais públicas.

A educação é cada vez mais modelada para atender às necessidades do mercado, ordenada pelos ajustes e políticas de austeridade, medidas socioeconômicas e ideológicas de enfrentamento da crise de rentabilidade e acumulação do capital (ANTUNES, 1999). Configuram-se, na educação superior, as ídeo-políticas de uma universidade operacional (CHAUÍ, 2003), empresarial e flexível, sintonizada com a lógica do mercado e dos negócios, com os interesses dos grandes grupos privados empresariais mercantis, internacionais e nacionais.

Do ponto de vista organizacional e do mercado, são empresas de educação com acentuada atuação competitiva, com cursos, matrículas e contratos flexíveis e com o trabalho docente, na maioria delas, objetivado em redes de computadores com a incorporação das Tecnologias de Informação e Comunicação (TICs) no setor de serviços.

Sobre o discurso pedagógico da acumulação flexível, Kuenzer (2018, p. 338) analisa que "a aprendizagem flexível surge como uma das expressões do projeto pedagógico da acumulação flexível, cuja lógica continua sendo a distribuição desigual do conhecimento, porém com uma forma diferenciada".

Essas mudanças são centrais na arquitetura organizacional dessas IES, nas relações de trabalho e de poder, assim como na capacidade de atender ao mercado. Segundo Chaves (2015, p. 430), "o estímulo à competitividade entre as instituições, direcionando-as para o mercado, com a finalidade de contenção dos gastos públicos, passa a ser a tônica das propostas e projetos dos sucessivos governos neoliberais instalados no mundo do capital".

Um contexto histórico no qual se generalizam os ataques à universidade pública, em que são agenciadas contrarreformas trabalhistas com foco no funcionalismo público, incluindo 
a precarização das condições de trabalho e a flexibilização dos contratos e concursos de docentes da educação superior, e em que se intensifica a terceirização na gestão universitária pública. Isso enquanto as IES privadas mercantis abastecem o mercado com o barateamento de cursos de graduação - licenciaturas e bacharelados a preços abjetos.

Ou seja, o que se enfatiza é a ideia de que a legalização e a expansão de instituições privadas com fins lucrativos e para fins comerciais estão coligadas à desnacionalização e a financeirização da educação superior. São empresas de ensino superior com prioridade para a obtenção de lucros financeiros no mercado de capitais e, claro, com o sequestro dos fundos públicos. Assim, não faz nenhum sentido para essas IES a defesa da autonomia universitária e da liberdade intelectual assim como o desenvolvimento da extensão, da pesquisa e da produção do conhecimento científico e tecnológico de interesse social.

A proposta dessa discussão advém da hipótese de que a expansão dos cursos de Serviço Social sob essa lógica privatista mercantil, com forte apelo aos valores do neoconservadorismo, é uma tendência incompatível e antípoda dos princípios, diretrizes, núcleos de fundamentação e conteúdos postulados nas Diretrizes Curriculares de 1996.

Nesse sentido, propõe-se, mais de duas décadas depois, seguir corroborando com as reflexões de Netto (1996): a direção estratégica do projeto ético-político mantém-se no centro dos embates e polêmicas profissionais. Obviamente, os embates se modificam quando um discurso de claro cunho ideo-político, neoconservador e ultraliberal se diz contrário ao projeto ético-político-profissional, à pesquisa científica e à teorização histórica e analítica que subjazem aos fundamentos de uma formação profissional que implica em "apreensão crítica do processo histórico como totalidade e a investigação sobre a formação histórica e os processos sociais contemporâneos que conformam a sociedade brasileira, no sentido de apreender as particularidades da constituição e o desenvolvimento do capitalismo e do Serviço Social no país" (ABEPSS, 1996).

\section{Neoliberalismo, ofensiva conservadora e financeirização da educação superior.}

No Brasil, as reformas e contrarreformas instauradas por governos liberais/neoliberais deixaram um profundo lastro de mercantilização da educação superior, convertida em produto de valor "acessível" por meio da diversificação na configuração das IES - priorizam-se faculdades e centros universitários e alternativas de modalidades de ofertas de cursos de 
graduação semipresenciais e à distância.

Nos últimos governos, a política tem sido a de imprimir uma lógica mercantil e empresarial à universidade brasileira, estimulando a sua privatização, segundo o que Chauí $(1995 ; 1999)$ denomina de "Universidade Operacional" ou "Universidade de Resultados e Serviços". Essa outra concepção de universidade é condizente com as recomendações dos organismos multilaterais, que tiveram abrigo nos Governos Cardoso com sua Reforma do Estado e se afirmam no atual governo (IAMAMOTO, 2015, p.433).

As orientações dos organismos internacionais e governos nacionais para a educação superior - diversificação institucional, flexibilidade nas modalidades e organização dos cursos, currículos e minimização dos conteúdos de formação, expansão exponencial de instituições privadas mercantis, prioridade para o ensino à distância e semipresencial - asseguram a institucionalização de uma educação superior, na lógica mercantil, como serviço e não como direito social. O trato comercial da educação superior instaura um processo de massificação mercantilizadora (SGUISSARDI, 2015). E essa combinação nefasta entre massificação e mercantilização aprofunda a desigualdade social no Brasil, acentuando a enorme dívida social no acesso e na permanência na educação superior.

Quanto ao acesso à educação superior, o fator determinante que mantém o Brasil no terço de menor cobertura ou taxa líquida dentre os países da América Latina, apesar de ser a $7^{\mathrm{a}}$ economia (PIB) do planeta, é a imensa desigualdade social que aqui se verifica. É ela, certamente, como amplamente demonstrado, o principal fator de produção da expansão elitista da educação superior, tanto na graduação como na pós-graduação. E aqui vale chamar a atenção para o duplo sentido do elitismo: a) como pertencimento a uma população, que não chega a $1 / 5$ do total da faixa etária adequada que tem acesso à educação superior; e como qualidade superior de formação, que somente é possível em raros casos na graduação e na pós-graduação, está acessível a menos de 5\% dos concluintes da graduação (SGUISSARDI, 2015, p. 870).

A educação superior mercantilizada é respaldada por lei, com mecanismos predominantes em governos neoliberais/ultraliberais e, como bem analisa Chaves, situa-se dentro das novas estratégias de acumulação de capital no setor educacional:

É oportuno ressaltar que as novas estratégias de acumulação de capital no setor educacional por meio do mercado de capitais, que se tornaram factíveis para um grupo de Instituições de Ensino Superior - IES mercantis, fazem parte das transformações ocorridas no mercado financeiro mundial, a partir dos anos 1970, de liberação e desregulamentação dos fluxos financeiros, da interligação dos mercados, da criação de inovações financeiras (derivativos, securitização, contratos futuros, etc.) e de fundos de investimentos institucionais, que estudiosos denominam de processo de "financeirização". O fenômeno tomou grandes proporções na economia americana e tornou-se bastante evidente nos países desenvolvidos (CHAVES, 2016, p. 2).

Em características mais gerais, são as mudanças radicais que operaram no contexto 
histórico pós-1973/1974, demarcado por um esgotamento da chamada "Era de Ouro" (pósSegunda Guerra), como bem apreendeu Hobsbawm (1995). Com a emergência da crise manifestada na queda tendencial da taxa de lucro, evidenciou-se certo esgotamento do padrão de acumulação sustentado no binômio fordismo/taylorismo, desencadeando, também, a ruptura com o ideário social-democrata, expresso no compromisso social do Welfare State.

O neoliberalismo, a privatização do Estado, a desregulamentação dos direitos do trabalho e a desmontagem dos setores produtivos estatais compõem, com o intenso processo de reestruturação da produção com predominância no toyotismo, as estratégias de reorganização do capital e de seu sistema ideológico e político de dominação. São os ajustes, as medidas socioeconômicas e ideológicas de enfrentamento da crise de rentabilidade e acumulação do capital (ANTUNES, 1999; 2018).

Essas experiências representaram e representam o trânsito para um regime de acumulação flexível, apoiado na flexibilidade dos processos de trabalho, na especialização flexível, flexibilidade dos mercados de trabalho, dos produtos e padrões de consumo.

O esboço de Harvey de interpretação teórica da transição do regime de acumulação dominante do capitalismo enfatiza que a acumulação flexível ainda é uma forma de capitalismo e suas características "mostram-se mais como transformações da aparência superficial do que como sinais do surgimento de alguma sociedade pós-capitalista ou mesmo pós-industrial inteiramente nova" (HARVEY, 1993, p. 12).

No ensino superior, por exemplo, os cursos aligeirados, flexíveis e a oferta de uma formação com o menor custo adequam a educação a esse processo de acumulação flexível. "A educação requisitada pelo capital deve ser 'ágil', 'flexível' e 'enxuta', como são as empresas geridas pelo sistema toyotista. Não foi por acaso que as grandes corporações inventaram a "universidade corporativa" (ANTUNES e PINTO, 2017, p. 100).

No campo da educação superior, a diversificação e a flexibilidade dos arranjos institucionais e as fusões tornaram factível a investida no mercado financeiro para um grupo de instituições. No Brasil, algumas das principais empresas de ensino de capital aberto atuam, inclusive, no segmento educacional da BM \& Bovespa. Destacam-se, nesse segmento, os grupos: Kroton ( marcas: Anhanguera, Unopar e Pitágoras), Estácio, Unip, Laureate (marcas: FMU, Anhembi-Morumbi, UniRitter), Cruzeiro do Sul Educacional (marcas: Universidade Cruzeiro do Sul, Colégio Alto Padrão), Ser Educacional (marcas: Uni Nassau, Univeritas), Uninove, Anima, Unicesumar, Adtalem Global Education (marcas: Damásio, Ibmec e Wyden). 
Empresas e grupos internacionais como Laureate Educacional - conglomerado norte-americano com inserção em diversos países.

Pela discussão de Mancebo $(2019 ; 2017)$ sobre as mudanças ocorridas no mundo do trabalho, particularmente sobre o regime de acumulação flexível e as demandas que geram para a formação, compreende-se por que a educação superior no Brasil bem exemplifica a flexibilização no campo educacional.

Atualmente, na educação superior brasileira, a tendência à flexibilização do sistema é uma realidade, designada oficialmente como educação terciária termo proposto pelo Banco Mundial, em título de 2003 -, que confunde, não raramente, a educação superior com ensino pós-secundário, compreendendo: tutorias remotas, encurtamento de carreiras, flexibilização de currículos, importação de modelos educativos baseados na "aquisição de competências profissionais", certificação de saberes e destrezas, reciclagem de competências. Mesmo a designação do trabalho do professor propriamente dito vem sendo transmutado de trabalho docente para "facilitador", "animador", "tutor" e "monitor", dentre outras novidades (MANCEBO, 2019, p. 21).

A educação superior flexível e mercantilizada é um investimento lucrativo. Daí que sua localização e as modalidades semipresencial e à distância sejam estratégicas para que se possa polarizar economicamente uma região nos seus diversos níveis.

Nessa conjuntura, a educação a distância realiza uma importante tarefa no setor educacional mercantil, imediatamente privado e com apoio direto do Estado, apresentando-se como um nicho de mercado altamente lucrativo, institucionalmente organizado em conformidade à racionalidade administrativa empresarial (MARTINS e VALE, 2019, p. 57).

Nesse sentido, a expansão do sistema com diversificação e diferenciação de tipos de instituição e a configuração da universidade operacional visam a assegurar uma dinâmica e um funcionamento organizacional que patenteiem a cultura incorporada às características típicas de mercadoria, cultura de consumo e sensibilidade consumidora.

O padrão flexível pretendido pelo grande capital para a instituição universitária é o de submeter todas as suas funções de ensino, pesquisa e extensão à dinâmica do mercado, garantir o produtivismo do ethos capitalista com a ciência cada vez mais confinada às exigências da inovação e da tecnologia, com ela própria convertida em produto mercantil. No atual contexto, "uma escola ampla no restrito espaço do ideário e da programática burguesa, uma educação moldada pelos 'valores do mercado', por sua 'filosofia' utilitarista, eis a nova dogmática da educação da era do capital flexível” (ANTUNES e PINTO, 2017, p. 97)

Nesse sentido, é possível entender por que as estratégias de Estado para a pesquisa e a pós-graduação passam a privilegiar o desenvolvimento de projetos de investigações na fronteira 
do conhecimento e em áreas e campos científicos com potencial de inovação, tendo em vista a produção de patentes e a prestação de serviços, de preferência com cooperação internacional, com possibilidade de produção em larga escala e em breve espaço de tempo.

Mudanças que levam ao esvaziamento da formação como núcleo central do trabalho na universidade, a subordinação de suas funções e de seus resultados a sistemas de inovação dos países sob o comando de políticas macroeconômicas. As atividades de pesquisa e os financiamentos passam a ser obtidos por editais e parcerias com organizações externas, com prioridade para a oferta e a criação de startups, empresas juniores e pesquisas associadas às novas tecnologias de informação. As mudanças nos sistemas de avaliação passam a acentuar a importância dos rankings nacionais e internacionais, a excelência, a produtividade, o prestígio e a competitividade, criando a "universidade de classe mundial" como um modelo de referência. No que se refere à formação de recursos humanos, são instituídos mecanismos de flexibilidade da pós-graduação stricto sensu, com os mestrados profissionais e, mais recentemente, a pósgraduação à distância.

A flexibilização dos processos de associação entre instituições, a constituição de diversas formas legais de consórcios ou parcerias entre instituições públicas e privadas e a flexibilização das fontes de financiamento servem à desnacionalização e à financeirização da educação. O experimento da 'universidade corporativa' é propagado para todo o espaço da educação formal, "em todos os seus níveis, do ensino básico à pós-graduação" (ANTUNES e PINTO, 2017, p.100).

Nesses moldes capitalistas e nessa direção, dentro da lógica mercantil e financeira, a universidade operacional, empresarial e mercantil é útil, funcional e orgânica à era da acumulação flexível do capital (HARVEY, 1993). Como sumaria Chauí (2003, p.11), “em outras palavras: a absorção do espaço-tempo do capital financeiro e do mercado da moda conduz ao abandono do núcleo fundamental do trabalho universitário, qual seja, a formação".

O racionalismo mercantil e as contrarreformas da educação formulam uma concepção de educação flexibilizada.

Essa é a moldura que as chamadas 'reformas da educação' trazem embutidas em sua concepção: uma escola (e uma 'educação) flexibilizada para atender às exigências e aos imperativos empresariais; uma formação volátil, superficial e adestrada para suprir as necessidades do mercado de trabalho 'polivalente', 'multifuncional' e flexível. Não é difícil perceber que a 'educação' instrumental do século XXI, desenhada pelos capitais em sua fase mais destrutiva, não poderá desenvolver um sentido humanista e crítico, que deve singularizar as ciências humanas; ao contrário, poderá concebê-las como 
decalque das ciências exatas, como um prolongamento residual quiçá desnecessário (ANTUNES e PINTO, 2017, p. 104, grifo dos autores).

Nessa Investigar, analisar e inquerir criticamente esse contexto de profunda transformação na educação superior e, em particular, no campo da formação profissional em Serviço Social são um imperativo que requer, com certeza, cada vez mais esforços teóricoanalíticos coletivos, norteados por uma concepção de educação humanista, crítica e omnilateral.

\section{Os Fundamentos do Serviço Social e as Diretrizes Curriculares Nacionais da Associação Brasileira de Ensino e Pesquisa em Serviço Social (ABEPSS), de 1996.}

Nas duas últimas décadas, a formação profissional em Serviço Social tem enfrentado novos desafios conjunturais, político-pedagógicos e educacionais. A expansão da educação superior no Brasil nos governos de Fernando Henrique Cardoso e, posteriormente, nos governos de Luís Inácio Lula da Silva e Dilma Rousseff sustentou, com apoio político e financeiro governamental, a rede institucional privada em detrimento de investimentos nas universidades públicas, conforme analisou Boschetti (2004). A crescente oferta de instituições de ensino impactou também na oferta de cursos e vagas disponíveis para o Curso de Serviço Social.

Em artigo publicado em 1996, Netto analisou as transformações societárias e os rumos que o Serviço Social percorreria a partir dos anos de 1990, apontando que o debate profissional caminharia, em curto/médio prazos, em torno da direção social que se afirmou nas décadas de 80 e 90. E ressaltou que "o que estará no centro da polêmica profissional será a seguinte questão: manter, consolidar e aprofundar a atual direção estratégica ou contê-la, modificá-la e revê-la” (NETTO, 1996, p. 117).

Para contribuir com o debate critico-analítico sobre o projeto de formação profissional propugnado nas Diretrizes Curriculares de 1996 e o reconhecimento do Serviço Social como área de conhecimento e avanços qualitativos conquistados e legitimados no contexto contraditório da Universidade, é preciso, mesmo que de modo resumido, percorrer os vetores e as linhas de forças que propiciaram a consolidação do processo de renovação do Serviço Social brasileiro e a afirmação de uma direção social estratégica em uma vertente de ruptura com o conservadorismo.

É exatamente aí que o conservadorismo e as proposições pós-modernas se dão as mãos: o combate e a crítica ao ideal de socialidade posto pelo programa da modernidade jogam claramente no sentido de desqualificar a direção social que se constituiu contra o conservadorismo. Eis porque, aqui, investir na pós- 
modernidade é também levar água ao moinho do conservadorismo (NETTO, 1996, p. 118).

No Brasil, as tendências críticas que despontaram, dentro e fora dos espaços acadêmicos, a partir da década de 1970, se aprofundaram nas décadas de 1980 e 1990 no sentido de, progressivamente, saturar as várias instâncias de organização da profisssão (sindical, profissional e acadêmica) numa direção social que, ao explicitar a sua dimensão política, abriria um caminho divisor na sua trajetória.

O caminho afirmaria um Serviço Social maduro, sob os contornos de um debate cultural e da compreensão de que as diferenciações e as tendências na profissão não se fazem inteligíveis em termos estritamente metodológicos, mas também nas determinações ideo-culturais, que influenciam as direções sociais que se movem como campos de alternativas na profissão.

Assim, durante as décadas de 1980 e 1990, a ampliação e a redefinição da organização profissional foram altamente reforçadas como exigência para se alcançar a construção de um projeto coletivo do Serviço Social. As entidades representativas da categoria impulsionaram o processo e avançaram na confluência entre os vetores políticos e os teóricos, fortalecendo o reconhecimento e a afirmação acadêmica da área, a constituição de um corpus teórico na área e o processo de organização política dos assistentes sociais (FARIA, 2014).

Um conjunto de conquistas e avanços teóricos, incontestavelmente, pôs em movimento uma vertente e um projeto de ruptura com o conservadorismo no horizonte da emancipação humana (ABRAMIDES, 2019). Apesar de sua extrema diversidade, o projeto profissional que ganhou vigor, materialidade e legitimidade apresenta fundamentos sócio-histórico, teóricometodológico e ético-políticos de uma nova cultura com enfoque nas análises históricas sobre a sociedade capitalista, a questão social e as dimensões profissionais.

O resgate dos pontos de conexão, das confluências e das contradições e limites que marcaram a profissão oferece os elementos que possibilitam apreender que o projeto éticopolítico profissional foi e é, efetivamente, uma conquista do Serviço Social brasileiro, um projeto original, inédito e não episódico, em decorrência dos seus vínculos com a organização profissional fundada nos princípios da livre e autônoma organização dos trabalhadores, da liberdade e autonomia sindical, da criação de sindicatos classistas e de luta.

Assim ao prevalecer um projeto profissional amplo e estratégico que, "exprimindo a própria inserção do Serviço Social na malha das concretas relações da sociedade brasileira" (NETTO, 1996, p. 108), se afirmaria entrelaçado às tendências da organização política da 
categoria, das diretrizes para a formação acadêmica do assistente social, com as contribuições da pesquisa e da produção de conhecimentos ancoradas na ontologia marxista e, fundamentalmente, comprometido com o desenvolvimento de uma nova legitimidade social das alterações conquistadas como competências socioprofissionais.

Esses traços contam favoravelmente para o desenvolvimento da investigação/pesquisa social no Serviço Social brasileiro à medida que também estimulam a explicitação das tradições teóricas, ideológicas, axiológicas e políticas que informam as distintas vertentes do pensamento social (positivismo e a tradição positivista, a fenomenologia, a teoria social de Marx e a tradição marxista).

A reformulação dos fóruns e das pautas profissionais ao mesmo tempo subsidia o processo de revisão da formação profissional, tanto na graduação quanto na pós-graduação, e coloca novas exigências para a ABEPSS, em particular.

Na construção dessa direção social se instauram os vetores que, juntos, contribuem para repensar os fundamentos teórico-metodológicos de interpretação da profissão, enraizados na análise do processo de produção e reprodução das relações sociais capitalistas.

Do ponto de vista da profissão, é incontestável a importância da produção teórica que analisa o pensamento conservador no Serviço Social. No momento em que, na pesquisa e na produção de conhecimento, constrói-se a análise crítica do universo cultural conservador do qual o Serviço Social é herdeiro, permite-se a incorporação de novas abordagens e conteúdos na formação profissional assim como a configuração e a formulação de novos projetos profissionais.

Conforme Netto (1991), a reflexão profissional no Brasil desenvolveu, entre as décadas de 60, 70 e 80, três direções principais por ele denominadas de perspectiva modernizadora, perspectiva de reatualização conservadora e de intenção de ruptura com o Serviço Social tradicional.

As suas reflexões sobre as vertentes teórico-profissionais intensificaram o debate profissional ao projetar que

verificar-se-á o desenvolvimento de uma vertente neoconservadora, inspirada fortemente na epistemologia pós-moderna (...)" e "assistir-se-á um florescimento de vertentes aparentemente radicais, abertamente desqualificadoras da teorização sistemática e da pesquisa rigorosa fundada seja num anticapitalismo romântico de inspiração católica, (...) seja no relativismo mais primário. (NETTO, 1996, p. 127).

No âmbito da formação profissional, é exatamente nas décadas que separam o artigo de 
Netto (1996) dos dias atuais que se registram os resultados da expansão na educação superior no Serviço Social com a abertura de cursos na modalidade EAD, com números de vagas desordenados e criados, em sua maioria, por IES privadas mercantis.

Os estudos realizados por Pereira e Souza (2019) evidenciam que, no final da segunda década do século XXI

a maioria das matrículas dos cursos de Serviço Social encontra-se em cursos de Serviço Social ofertados na modalidade de $\mathrm{EaD}$ e, nos cursos presenciais, a maior parte encontra-se em IES mercantis. Essa caracterização nos leva a questionar o perfil de profissional que vem sendo formado nas duas últimas décadas, em um contexto de profunda mercantilização do ensino superior brasileiro e de uso intensivo do EaD como estratégia de expansão e maximização de lucros (PEREIRA e SOUZA, 2019, p. 213).

Nos embates que se movimentam nos espaços de formação, no trabalho profissional e nos movimentos e organizações das/dos assistentes sociais e do movimento estudantil, observam-se os efeitos de um movimento irregular, porém inequívoco, de crescimento da modalidade de ensino à distância.

A despeito do movimento irregular, durante o período considerado entre o ponto inicial e o final, foi possível verificar uma ampliação significativa de 198,18\% do número de matrículas em cursos de Serviço Social ofertados na modalidade de EaD; um percentual claramente superior que os $15,15 \%$ dos cursos de Serviço Social presenciais. (PEREIRA e SOUZA, 2019, p.124).

$\mathrm{Na}$ perspectiva dos fundamentos históricos e analíticos do Serviço Social, vêm-se desenvolvendo estudos e investigações com a finalidade de desvelar os processos, mudanças e contradições inerentes à relação trabalho e educação sob as exigências e determinantes do padrão de acumulação flexível. Nos termos de Pereira e Souza, é necessário aprofundar o conhecimento "de como efetivamente vem se desenrolando o processo formativo dos assistentes sociais brasileiros, o que nos auxiliará a fornecer pistas e estratégias para enfrentar os inúmeros limites e desafios ao processo formativo" (PEREIRA e SOUZA, 2019, p. 114).

Uma prioridade inscrita na agenda nacional de investigação e produção de conhecimentos críticos, pertinente à graduação e, em especial, aos programas de pós-graduação stricto sensu, grupos de pesquisas e grupos temáticos de pesquisa da ABEPSS, considera os desafios à formação profissional na seguinte medida

Talvez a mais importante mudança trazida pelas novas bases materiais de produção seja a mudança de eixo na relação entre trabalho e educação, que deixa de priorizar os modos de fazer para contemplar a articulação entre as diferentes formas e intensidades de conhecimento, tácito e científico, com foco no enfrentamento de situações não previstas.(KUENZER, 2016, p. 40). 
A pesquisa de Pereira e Souza sobre a formação profissional em Serviço Social analisa uma década de expansão, de 2007 a 2017, com base em indicadores quanto ao número de cursos presenciais e cursos em EAD, número de vagas ofertadas em cursos de Serviço Social presenciais e vagas ofertadas em curso na modalidade EAD, número de matrículas em cursos presenciais e a distância e número de ingressos e de concluintes nas duas modalidades (PEREIRA e SOUZA, 2019).

No decurso de uma década de expansão, conferem as autoras, "na área do Serviço Social, o processo de mercantilização assinalado impactou transversalmente a profissão e trouxe consequências que ainda merecem pesquisas de forma mais aprofundada" (PEREIRA e SOUZA, 2019, p. 113).

Exemplifica o raciocínio das autoras sobre o mercado educacional no Serviço Social o número exponencial, geométrico de vagas ofertadas na modalidade de cursos à distância. Nos cursos presenciais, as vagas ofertadas em 2007 estavam na faixa de 30.331. Em 2017, foram 49.081 vagas, o que representa um crescimento de $61,81 \%$. Em outro patamar, o número de vagas ofertadas em cursos de Serviço Social EAD registrou um crescimento, no mesmo período, de 156,37\%: em 2007, como oferta efetiva de vagas, o número era de 51.836; em 2017, foram ofertadas 132.895 vagas. (PEREIRA e SOUZA, 2019).

Diante da importância inegável das Diretrizes Curriculares para a formação profissional de assistentes sociais no Brasil e os desafios postos pela expansão mercantil da educação, é mister aprofundar, renovar e avançar nas investigações e teorização dos fundamentos norteadores da análise do significado social e histórico da profissão inserida na divisão social e técnica do trabalho. "Esta perspectiva destaca, fundamentalmente, a historicidade do Serviço Social entendido no quadro das relações entre as classes e destas com o Estado" (ABEPSS, 1996, p.5).

Na particularidade da sociedade brasileira, o projeto de formação do Serviço Social concebe as dimensões teórico-metodológica, ético-política e técnico-operativa como dimensões e núcleos dos fundamentos do Serviço Social: o primeiro, fundamentos teórico-metodológicos da vida social; o segundo, fundamentos da formação sócio-histórica da sociedade brasileira; e o terceiro, o núcleo de fundamentos do trabalho profissional - todos eles confirmados nas Diretrizes da ABEPSS:

Desta forma, entende-se que a efetivação de um projeto de formação profissional, remete, diretamente, a um núcleo de conjunto de conhecimentos indissociáveis, que se traduzem nos Núcleos de Fundamentação constitutivos da formação profissional. (ABEPSS, 1996, p. 8). 
As Diretrizes Curriculares do Serviço Social sobrelevam a relação entre formação, áreas de conhecimento, conteúdos e componentes curriculares na perspectiva dos núcleos de fundamentos. No conjunto, destacam-se os fundamentos históricos e teórico-metodológicos do Serviço social:

Análise da trajetória teórico-prática do Serviço Social no contexto da história da realidade social e as influências das matrizes do pensamento social. $\mathrm{O}$ trabalho profissional no processo de produção e reprodução social em relação às questões sociais nos diferentes contextos históricos. (ABEPSS, 1996, p. 17)

Os conteúdos, as disciplinas e os núcleos de fundamentos inseridos nas matrizes curriculares das IES abordam muito mais que a historiografia da profissão.

As disciplinas de Fundamentos, ao trazerem em cena a história da profissão, fazem-no de forma articulada com os núcleos que fundamentam as diretrizes curriculares. Ou seja, não se esgotam em si mesmas, remetem a uma abordagem do conteúdo cujo veio articulador é a história, mas a "história ético-política" que leva em conta o aprofundamento do processo histórico de forma integral e não de forma parcial e intrínseca (Gramsci, 1999), resgatando o movimento integral da sociedade em todas as suas determinações, e, neste, o movimento da própria profissão. É nesse olhar, essa compreensão da sociedade, da história e da própria profissão que permite dar suporte e conteúdo às disciplinas. Estuda-se a história, mas com um olhar particular, voltado à identificação das questões sociais e de suas determinações nas diferentes conjunturas históricas e políticas. (SIMIONATO, 2004, p. 34).

As Diretrizes dispõem que cada IES pode elaborar seu currículo pleno, mas seguindo as normas aprovadas para o Curso de Serviço Social: respeito à lógica da formação profissional com a prioridade ontológica da totalidade na apreensão da sociabilidade burguesa como questão central no estudo do processo de produção e reprodução das relações sociais capitalistas. $\mathrm{Ou}$ seja, demarcando, sobremaneira, a sua diferença com a retórica da flexibilização curricular e de conteúdo, marca dos cursos eles próprios flexíveis.

Esse princípio constava nas diretrizes da ABEPSS como "flexibilidade e dinamicidade dos currículos plenos, expressa na organização de disciplinas e outros componentes curriculares, tais como: oficinas, seminários, estágio, atividades complementares. Evidente que não se trata de flexibilizar os conteúdos, e sim dar maior maleabilidade na organização dos conteúdos e assegurar as especificidades regionais. (BOSCHETTI, 2004, p. 24).

$\mathrm{Na}$ lógica de uma educação mercantil e massificante, delineiam-se problemas, desafios e embates advindos de processos judiciais movidos por corporações educacionais contra o CFESS e sua atuação em defesa das Diretrizes Curriculares, dos princípios éticos norteadores da profissão por meio do Código de Ética do Assistente Social e das conquistas a partir da Lei $\mathrm{n}^{\circ} 8.662 / 1993$ que regulamenta a profissão. 
Na dimensão pedagógica, enfrentam-se as contradições de uma expansão de cursos de graduação de Serviço Social com base em currículos frágeis e com exigências de um perfil profissional moldado pela lógica mercadológica e pela instrumentalização tecnocrática do conhecimento científico e dos saberes profissionais (AVELAR, 2019).

Respaldado em Kuenzer (2016), é possível assinalar que o que não se revela no discurso pedagógico da acumulação flexível se processa em metodologias de aprendizagens e de formação de subjetividades flexíveis que derivam da negação da práxis como possibilidade de transformação, princípio que fundamenta as teorias pós-modernas.

Para a formação profissional e a cultura intelectual da profissão, consolidadas ao longo de sua renovação teórico-metodológica e ética, abrem-se lacunas no nível da graduação, na aprendizagem e no perfil profissional, com base na fragmentação dos fundamentos teóricometodológicos, ético-políticos e técnico-operativos e o conhecimento cientifico e intelectual acumulado pela teorização na área de Serviço Social (NONATO, 2017).

Assim, é necessário indagar e pensar sobre processos pedagógicos de formação em um contexto em que se processa um conjunto de estratégias de mercantilização e financeirização da educação associada a uma cultura regressiva, conforme criva Antunes (2018), de devastação dos direitos do trabalho, dos direitos sociais e de forte apelo aos valores do neoconservadorismo.

Nas contribuições analíticas de Kuenzer (2016), são processos de aprendizagem que definem os contornos da subjetividade flexível, objeto dos processos pedagógicos de formação que visam à reprodução ampliada do capital.

Diante do exposto, entende-se que o conteúdo abertamente ideológico e político de um tipo de discurso que objetiva pôr em causa os valores que incidem sobre a formação e o trabalho profissional ao se projetarem as possibilidades históricas de um futuro de educação para além da sociabilidade burguesa precisa ser desvelado com o mesmo rigor teórico-metodológico com que, no Brasil, se desenvolve a capacidade de reflexão e de crítica do pensamento conservador contemporâneo no universo cultural do Serviço Social, sua institucionalidade e reatualizações.

Assim, é necessário dar continuidade aos debates e às polêmicas profissionais adensados pela racionalidade teórica crítico-dialética que orienta o crescente domínio dos conhecimentos científicos que desmitificam as expressões conservadoras e neoconservadoras de uma ordem societária que opera com a socialização de um mundo fetichizado por meio da educação, da mídia, do desenvolvimento de um sistema mundial de informações e com novos padrões de 
produção e acumulação do capital.

Tal representa também resistir e potencializar, na categoria profissional, na articulação teórica e política, uma concepção de educação humanista, ilustrada, democrática e universal, a defesa da universidade pública como instituição social em contraposição à universidade operacional, empresarial, mercantil e útil ao padrão de acumulação flexível do capital. Conforme sumariou Pereira (2016), o cultivo, no Serviço Social, de uma cultura de oposição ao conservadorismo tem conseguido persistir e manter viva a disposição de fazer frente ao radicalismo burguês. "E com essa tendência - que não é unânime, mas historicamente persistente -, ele tem sido um profícuo "ponto fora da curva" das profissões sucumbentes ao conservadorismo" (PEREIRA, 2016, p. 414).

\section{Considerações finais}

No Brasil, as múltiplas alterações e desregulamentações na legislação educacional são contrarreformas com a finalidade de derrubar barreiras constitucionais, jurídicas e sociais e, ao mesmo tempo, criar condições legais e institucionais para a expansão de uma educação superior privada e mercantil, de venda massificada de um ensino sem pesquisa e extensão, desprovido de abordagens e dimensões educativas múltiplas e existentes no ato formativo e de aprendizagem.

$\mathrm{Na}$ universidade-empresa, como uma mercadoria de um negócio privado, é suprimida da formação a coexistência entre as possibilidades de uma educação que contempla a formação profissional integral e que valoriza a perspectiva sócio-histórica do conhecimento científico, para favorecer, exclusivamente, o consumo e a repetição de conteúdos e reprodução de modelos.

No Serviço Social, no que se refere à lógica contemporânea do pensamento conservador, a expansão e a oferta de cursos de graduação - principalmente os da modalidade à distância contrapõem-se ao projeto profissional norteador da formação profissional.

Há, na categoria, com a coordenação e a representatividade das entidades do Serviço Social, um constante debate sobre como essa forma de ensino precariza a formação profissional do assistente social, seja na graduação presencial ou à distância. A ABEPSS produziu, no decorrer desses anos, campanhas públicas e elucidativas de seu posicionamento bem como grupos de trabalhos e de discussão para analisar a relação entre essa modalidade de ensino e a formação profissional em Serviço Social. 
O conjunto CFESS-CRESS juntamente com a ABEPSS e a ENESSO, e a partir do intenso debate sobre a formação profissional, elaboraram um documento, em dois volumes, sobre a incompatibilidade entre a graduação à distância e o Serviço Social. Nesses documentos, se condensam todas as discussões e o posicionamento da categoria sobre o ensino à distância não ser compatível com o Serviço Social.

Em 2011, foi lançada, também pelo conjunto CFESS-CRESS, ABEPSS e ENESSO, com apoio do Sindicato dos Docentes das Instituições de Ensino Superior (ANDES), a campanha nacional "CFESS Manifesta" em defesa da formação de qualidade - "Educação não é FastFood: diga não para a graduação à distância em Serviço Social” -, um manifesto crítico à contrarreforma universitária e seu caráter mercantil de ensino e à proliferação sem controle de cursos na modalidade à distância. Os seus conteúdos expressaram o compromisso das entidades com a educação superior laica, pública e de qualidade, orientada a atender às necessidades da população e a enfrentar a precarização e a mercantilização das políticas sociais e as desigualdades no país.

$\mathrm{Na}$ atual conjuntura em que se encontra o debate sobre a formação profissional, marcado pela regressão de direitos e pelo acirramento dos ataques às universidades públicas e federais, foi também fundamental o lançamento, em maio de 2019, ainda pelo conjunto CFESSCRESS, ABEPSS e ENESSO, da campanha "Graduação em Serviço Social só se for legal, crítica e ética". Essa iniciativa teve o objetivo de reafirmar as Diretrizes Curriculares, os princípios éticos que norteiam a profissão através do Código de Ética do Assistente Social e as conquistas a partir da Lei ${ }^{0} 8.662 / 1993$ que regulamenta a profissão.

As reflexões formuladas sobre a direção estratégica do projeto ético-políticoprofissional reafirmam, no atual contexto histórico do Brasil, o imperativo de preservar as Diretrizes Curriculares Nacionais do Serviço Social, defender a investigação rigorosa, sistemática e a produção de conhecimentos na área ancoradas nos fundamentos da Teoria Social de Marx, da tradição marxista e no pensamento crítico e fortalecer a resistência coletiva, classista e de lutas concretas

E, em particular, é preciso desvelar rigorosamente o modo pelo qual o capital vem enfrentando a sua crise de acumulação latente e evidente no pós-70, o que implica também em mudanças na esfera do jurídico-político. Os vínculos do Estado e do direito social com a organização do capitalismo monopolista e suas estratégias para administrar e enfrentar a crise de acumulação que assola os países centrais e periféricos acentuam a sua configuração 
burguesa, seu caráter de classe, justificam o redimensionamento de sua ação e o encolhimento de suas funções pela flexibilização e na desregulamentação.

A universidade operacional se enquadra de modo funcional e orgânico no padrão de acumulação flexível do capital. Um contexto histórico de projeção e mistificação $d a$ sensibilidade consumidora (NETTO, 1996) e da soberania do consumidor (MÉSZÁROS, 1999), que produz falsas contraposições entre políticas neoliberais e social-democratas (VIEIRA, 1997) e é criador da ambiência para a mitologia do mercado como regulador geral das relações societárias.

Cabe assinalar que não é necessário ter uma perspectiva marxista para inferir que o Serviço Social se configura como uma profissão imersa no movimento vivo da sociedade, notadamente das relações entre o Estado e a sociedade, que condicionam os seus avanços, tendências e limites.

No entanto, do ponto de vista do método em Marx, a análise de situações concretas e, consequentemente, do processo de produção e reprodução das relações sociais capitalistas, é central para estabelecer as particularidades observadas na trajetória do Serviço Social no Brasil.

O Serviço Social, quando analisado no contexto socioeconômico e das orientações que foram implementadas no país nas últimas décadas, requer dos seus profissionais, pesquisadores e intelectuais um debate e uma investigação que levem em conta o aprofundamento analítico da concretude, das bases materiais e da dinâmica das transformações societárias.

Conforme Mota (1998), identificar as mediações que conectam a experiência profissional às mudanças em curso é explicar o modo como se traduzem e o seu impacto na particularidade da profissão. E nessa perspectiva analítica avançar, renovar e aprofundar na ruptura com o conservadorismo afirmada como uma linha de força manifesta no contexto da renovação do Serviço Social brasileiro, ao confluir a aproximação com a tradição marxista e a direção social estratégica do projeto ético-político profissional.

\section{Referências bibliográficas}

ABEPSS. Associação Brasileira de Ensino e Pesquisa em Serviço Social. Diretrizes gerais para o curso de Serviço Social. Rio de Janeiro, 1996.

ABRAMIDES, M. B. C. O Projeto Ético-Político do Serviço Social Brasileiro: ruptura com o conservadorismo. São Paulo: Cortez, 2019.

ANTUNES, R. Os sentidos do Trabalho. Ensaio sobre a afirmação e a negação do trabalho. São Paulo: Ed. Boitempo, 1999.

. O privilégio da servidão. O novo proletariado de serviços na era digital. São Paulo: Boitempo, 2018.

ANTUNES, R.; PINTO, G. A. A fábrica da educação: da especialização taylorista à 
flexibilização toyotista. São Paulo: Cortez, 2017.

AVELAR, S. M. Formação Profissional, Fundamentos do Serviço Social e Ofensiva Conservadora na Educação Superior: a expansão dos cursos de serviço social no estado de Goiás. 2019, 129 f. Dissertação (Mestrado em Serviço Social). Escola de Ciências Sociais e da Saúde. Pontifícia Universidade Católica de Goiás, Goiânia-Goiás, 2019.

BOSCHETTI, I. O desenho das Diretrizes Curriculares e dificuldades na sua implementação. In $O$ Ensino e Trabalho Profissional: desafio para afirmação das diretrizes curriculares do projeto ético-político. Temporalis/ Associação Brasileira de Ensino e Pesquisa em Serviço Social. Ano 4, nº8 (jul./dez. 2004). Porto Alegre: ABEPSS, Gráfica Odisseia, 2004.

CHAUÍ, M. A universidade pública sob nova perspectiva. Revista Brasileira de Educação, n. 24, 2003.

CHAVES, V. L. J. Financeirização e Expansão do Ensino Superior privado-mercantil no Brasil. Disponível em http://www.aforges.org/wp-content/uploads/2016/11/8-Vera-JacobChaves_Financeirizac_a_o-e-Expansao-do-Ensino-Superior-privado-mercantil.pdf. Acesso em: 01 mar. 2020.

. Expansão da privatização do ensino superior brasileiro: a formação dos oligopólios. Revista Educ. Soc., Campinas, v. 31, n. 111, p. 481-500, abr.-jun. 2010 481. Disponível em http://www.cedes.unicamp.br Acesso em: 07 mar. 2020.

Política de financiamento e a expansão da educação superior no Brasil: o público e o privado em questão. Revista Educação Temática Digital, v. 17, n.2, pag. 427-441, 2015. Disponível em DOI: https://doi.org/10.20396/etd.v17i2.8635212. Acesso em: 07 mar. 2020.

FARIA, S. de. Reflexões contemporâneas sobre pesquisa e produção do conhecimento em Serviço Social no Brasil. Revista Praia Vermelha, v. 24, $\mathrm{n}^{\circ}$ 2. Serviço Social Latino-Americano: Questões Contemporâneas. Rio de Janeiro: UFRJ, p. 505-527, jul/dez. 2014.

HARVEY, D. A Condição Pós-Moderna. São Paulo: Loyola, 1993.

HOBSBAWM, E. Era dos Extremos. O Breve Século XX - 1914-1991. São Paulo: Companhia das Letras, 1995.

IAMAMOTO, M. V. Serviço Social em tempo de capital fetiche: capital financeiro, trabalho e questão social. 9 ed. São Paulo: Cortez, 2015.

KUENZER, A. Z. A formação dos trabalhadores no espaço de trabalho. In: Trabalho Necessário - www.uff.br/trabalhonecessario; Ano 14, No 25, 2016

MANCEBO. D. Acumulação flexível e educação superior: qual formação e para que força de trabalho? In $O$ ensino a distância na formação em Serviço Social: análise de uma década. VALE, A.A. do; PEREIRA, L.D. (organizadoras). 1. ed. -Rio de Janeiro: E-papers, p. 16-27 2019.

. Educação superior no Brasil: expansão e tendências (1995-2014). In: AZEVEDO, M. L. N. de; ROTHEN, J. C.; SILVA JÚNIOR, J. dos R.; SOUSA, J. V. de (Orgs.). Política de educação superior brasileira: apontamentos e perspectivas. 1. ed. Belo Horizonte: Fino Traço, p. 101-120.2017.

MARTINS, T. B.; VALE. A. A. do. A subsunção do trabalho docente na EaD e as políticas de desregulamentação do ensino superior brasileiro. In $O$ ensino a distância na formação em Serviço Social: análise de uma década. VALE, A. A. do; PEREIRA, L. D. (Org.). 1. ed. -Rio de Janeiro: E-papers, p. 54 - 69. 2019.

MARX, K. Para a Crítica da Economia Política. Trad. Edgard Malagodi. São Paulo: Abril Cultural, 1982. (Os Economistas).

MOTA, A. E. (Org.) A nova Fábrica de Consensos. São Paulo: Ed. Cortez, 1998.

MÉSZARÓS, I. O Poder da Ideologia. Trad. Magda Lopes. São Paulo: Ensaio, 1996.

NETTO, J. P. Ditadura e Serviço Social. Uma Análise do Serviço Social no Brasil pós - 64. São 
Paulo: Ed. Cortez, 1991.

. Transformações Societárias e Serviço Social. Notas para uma Análise Prospectiva da Profissão no Brasil. Revista Serviço Social e Sociedade n. 50, São Paulo: Ed. Cortez, 1996.

. Capitalismo e barbárie contemporânea. Revista Argumentum, Vitória (ES), v. 4, n.1, p. 202-222, jan./jun. 2012

. Para uma nova história do Serviço Social no Brasil. In: Serviço Social no Brasil: histórias de resistência e de ruptura com o conservadorismo. OLIVEIRA E SILVA, M. L. (Org.). São Paulo: Cortez, 2016.

NONATO, P. R. Formação em Serviço Social e a lógica da expansão do ensino superior brasileiro: um estudo dos cursos na modalidade a distância em Goiás. 2018, 185 f. Dissertação (Mestrado em Serviço Social). Escola de Ciências Sociais e da Saúde. Pontifícia Universidade Católica de Goiás, Goiânia-Goiás, 2018.

PEREIRA. P. A. P. Serviço Social: um enfant terrible na institucionalidade burguesa? Revista Serviço Social e Sociedade. São Paulo: Cortez, n. 127, p. 413-429, set./dez. 2016. http://dx.doi.org/10.1590/0101-6628.078

PEREIRA, L. D.; SOUZA, A. C. V.de. Formação profissional em Serviço Social no contexto de expansão mercantilizada: análise de uma década. In $O$ ensino a distância na formação em Serviço Social: análise de uma década. VALE, A. A. do; PEREIRA, L.D. (organizadoras). 1. ed. -Rio de Janeiro: E-papers, p. 109-137. 2019

SGUISSARDI, V. Educação Superior no Brasil. Democratização ou massificação mercantil? Revista Educação Social, Campinas. v.36, nº133, p. 867-889, out-dez. 2015.

SIMIONATTO, I. Fundamentos Históricos e Teórico-Metodológicos do Serviço Social. In $O$ Ensino e Trabalho Profissional: desafio para afirmação das diretrizes curriculares do projeto ético-político. Revista Temporalis. Ano 4, n. 8 (jul./dez. 2004). Porto Alegre: ABEPSS, Gráfica Odisseia, 2004.

VIEIRA, E. As Políticas Sociais e os Direitos Sociais no Brasil: Avanços e Retrocessos. Revista Serviço Social e Sociedade nº. 53. São Paulo: Cortez, 1997. 